\title{
Investigation on the Correlation between Inclusions and High Temperature Urea Corrosion Behavior in Ferritic Stainless Steel
}

\author{
Xuelin Wang ${ }^{1,2}$, Qingsong Lu ${ }^{3}$, Wei Zhang ${ }^{4,5}$, Zhenjia Xie ${ }^{1, *(1)}$ and Chengjia Shang ${ }^{1,2, *}$ \\ 1 Collaborative Innovation Center of Steel Technology, University of Science and Technology Beijing, \\ Beijing 100083, China; xuelin2076@ustb.edu.cn \\ 2 Yangjiang Branch, Guangdong Laboratory for Materials Science and Technology (Yangjiang Advanced Alloys \\ Laboratory), Yangjiang 529500, China \\ 3 Zhejiang Yinlun Machinery Co., Ltd., Taizhou 317299, China; luqingsong@yinlun.cn \\ 4 Central Iron \& Steel Research Institute, Beijing 100081, China; zhangwei3@citic.com \\ 5 CITIC Metal Co., Ltd., Beijing 100004, China \\ * Correspondence: zjxie@ustb.edu.cn (Z.X.); cjshang@ustb.edu.cn (C.S.)
}

Citation: Wang, X.; Lu, Q.; Zhang, W.; Xie, Z.; Shang, C. Investigation on the Correlation between Inclusions and High Temperature Urea Corrosion Behavior in Ferritic Stainless Steel. Metals 2021, 11, 1823. https://doi.org/10.3390/met11111823

Academic Editor: Francesco Iacoviello

Received: 14 October 2021

Accepted: 8 November 2021

Published: 13 November 2021

Publisher's Note: MDPI stays neutral with regard to jurisdictional claims in published maps and institutional affiliations.

Copyright: (c) 2021 by the authors. Licensee MDPI, Basel, Switzerland. This article is an open access article distributed under the terms and conditions of the Creative Commons Attribution (CC BY) license (https:/ / creativecommons.org/licenses/by/ $4.0 /)$.

\begin{abstract}
The influence of inclusion size and number density on high-temperature urea corrosion (HTUC) behavior of ferritic stainless steels was investigated in a simulated working environment of selective catalytic reduction (SCR) system in commercial vehicles. There is a positive correlation between the control level of inclusions and the resistance of HTUC. By slightly increasing the content of $\mathrm{Nb}$ in ferritic stainless steels, the inclusions, especially TiN, were significantly refined, and thus displayed an improvement in HTUC resistance. The interface between inclusions and the matrix becomes a fast channel for chromium precipitation during high-temperature nitriding induced by the decomposition of urea. Chromium nitrides will precipitate around the inclusions and wrap the inclusions, which will decrease the chromium equivalent of the matrix and reduce the resistance of ferritic stainless steels to HTUC. In addition, the high-temperature oxidation accompanied with thermal fatigue also makes the inclusions more likely to become the crack nucleation source, which can accelerate the material thinning and reduce its service life.
\end{abstract}

Keywords: ferritic stainless steel; corrosion; inclusion; Cr-rich precipitates; interfaces

\section{Introduction}

Due to their good corrosion resistance, good formability, good high-temperature oxidation resistance and lower cost compared to austenitic stainless steels, ferritic stainless steels have been gradually applied in the exhaust system of commercial vehicles [1-5]. In the exhaust system, a selective catalytic reduction (SCR) system used to decompose urea to form ammonia, which reacts with NOx in tail gas, has the worst working environment. Under the latest commercial vehicle arrangement, its maximum temperature can reach $700{ }^{\circ} \mathrm{C}$, and it is also affected by thermal fatigue [1]. Therefore, more stringent performance requirements are raised for material selection. A previous study [2] indicated that the addition of $\mathrm{Nb}$ and $\mathrm{Mo}$ is very beneficial to improve the high-temperature urea corrosion (HTUC) resistance of ferritic stainless steel, attributing it to the reduction of the reactivation rate. However, the addition of alloying elements is bound to lead to higher costs. Recent studies [6,7] have shown that adding $\mathrm{Nb}$ and $\mathrm{Ti}$ at the same time can play a double stabilizing role and refine inclusions to improve the condensate corrosion resistance of ferritic stainless steel. It means that inclusions are also one of the key factors affecting the corrosion resistance of materials.

Because of the inconsistency on electric potential between the inclusion and the matrix, when the inclusion exists on the steel surface, it is easy to form a micro cell circuit with the matrix, which causes galvanic corrosion and accelerates the nucleation and expansion of pitting corrosion [8,9]. Once it occurs, the cavity will form and propagate through the 
matrix dissolution around inclusions and detachment of particles [10]. Additionally, the fatigue crack generally initiates from a large inclusion, and the stress localization at the inclusion/matrix interface is the origin of fatigue cracking [11].

Previous studies [2] have clearly confirmed that the oxide layer and intergranular corrosion layer will be formed on the surface of ferritic stainless steel treated at the condition of high-temperature urea corrosion. Intergranular corrosion induced by nitriding due to decomposition of urea at high temperature is the key. The factors influencing intergranular corrosion include the environment temperature, medium, material composition, and grain size [12], and the latest study [13] shows that the element segregation at the grain boundary can also induce the formation of chromium poor zone, which leads to intergranular corrosion. However, up to now, no relevant research has been found to explore the relationship between inclusions and HTUC performance. Thus, inclusion is regarded as another key influencing factor and has been studied in this study. The aim is to elucidate the correlation between inclusion and properties of the steel. In this study, we elucidate the effect of inclusion content and size on the resistance of HTUC and clarify its mechanism, aiming to enhance the HTUC resistance and prolong the service life of materials by improving metallurgical quality.

\section{Material and Methods of Experiments}

Three kinds of 439 ferritic stainless steels with similar composition, similar processing but different inclusion contents were selected for this study. The chemical compositions are shown in Table 1. In order to present the actual working environment in the SCR system (National six, Wanxiang Tongda Co., Ltd, Shiyan, China) of commercial vehicle more accurately, the simulation experiment workstation was established. Its detailed equipment and working principle have been introduced in detail in [2]. As the latest emission standards are further improved, the service temperature of the SCR system has also changed. Based on this, the experimental scheme was adjusted to $700{ }^{\circ} \mathrm{C}$ at a high temperature and $350{ }^{\circ} \mathrm{C}$ at a low temperature. At the same time, the sample surface was sprayed with urea solution at the rate of $0.1 \mathrm{~mL} / \mathrm{s}$ during the thermal cycle. The size of the thermal simulation sample is $15 \mathrm{~mm}$ (length) $\times 10 \mathrm{~mm}$ (width) $\times 1.5 \mathrm{~mm}$ (thickness). Each thermal cycle is $325 \mathrm{~s}$ in total, including $150 \mathrm{~s}$ at high temperature and $100 \mathrm{~s}$ at low temperature. The total duration of the experiment was designed as $6 \mathrm{~h}$.

Table 1. Chemical composition of 439 ferritic stainless steels (wt.\%).

\begin{tabular}{cccccccccc}
\hline No. & $\mathbf{C}$ & $\mathbf{S i}$ & $\mathbf{M n}$ & $\mathbf{S}$ & $\mathbf{P}$ & $\mathbf{C r}$ & $\mathbf{N b}$ & $\mathbf{T i}$ & $\mathbf{A l}$ \\
\hline steel-1 & 0.01 & 0.33 & 0.24 & 0.001 & 0.016 & 17.59 & 0.18 & 0.19 & 0.035 \\
steel-2 & 0.01 & 0.24 & 0.13 & 0.001 & 0.017 & 17.93 & 0.33 & 0.22 & 0.032 \\
steel-3 & 0.01 & 0.29 & 0.16 & 0.001 & 0.015 & 17.37 & 0.35 & 0.25 & 0.022 \\
\hline
\end{tabular}

After completing the simulation experiments, the cross section samples in the thickness direction are cut and prepared by mechanical grinding and polishing and subsequently examined by using TESCAN MIRA3 field emission scanning electron microscopy (SEM, TESCAN, Brno, Czech Republic) in order to show urea corrosion products more clearly and facilitate the measurement of corrosion depth. Ten groups of corrosion depth values were measured in the urea sprayed zone of each sample, and the average values were used to characterize the total degradation degree, including the oxide layer and intergranular corrosion zone. In addition, the thickness reduction of each sample was measured by the same method. To explore the mechanism of inclusions on urea corrosion behavior, the samples without heat treatment were observed by optical microscope (OM, Olympus Corporation, Tokyo, Japan), and the content and size of inclusions were measured. Then, the inclusions in the urea corrosion zone and unaltered matrix were compared and calibrated by energy dispersive spectroscopy (EDS) using an Ultim Max170 detector in SEM. (Oxford Instruments, Oxford, United Kingdom) Additionally, the cross-section samples were etched with a solution of copper chloride, hydrochloric acid, and ethyl alcohol (1 g:8 mL:140 mL) 
to observe the difference of inclusion morphology between the two regions. Meanwhile, electron back-scattering diffraction (EBSD, Oxford Instruments, Oxford, UK) was used to characterize and measure the size of ferrite grain.

\section{Results and Discussion}

The OM images of inclusions in the three steels are shown in Figure 1a-c. The inclusions are spherical or elliptical, and the size decreases with the increase of the sample number (consistent with $\mathrm{Nb}$ content increment). Figure $1 \mathrm{~d}$ shows the statistical results of inclusions in five pictures of the same size. It can be found that the average size of inclusions in the three steels is $\sim 5$ to $7 \mu \mathrm{m}$, which is not very coarse. However, the maximum size and number density of steel- 1 are much larger than those of steel-3. These values obtained in steel-2 are between above two. This should be partly due to the low $\mathrm{Nb}$ content in steel-1, because $\mathrm{Nb}$ can form $\mathrm{NbC}$ or $\mathrm{Nb}(\mathrm{N}, \mathrm{C})$ around high-temperature TiN and inhibit TiN coarsening [14]. The inclusions in ferritic stainless steel will be refined with the increase of $\mathrm{Nb}$ content [6]. The other part of the reason should be attributed to the level of metallurgical technology. In the smelting process of ferritic stainless steel, Al-deoxidation is used to improve the yield of $\mathrm{Ti}$, but the high $\mathrm{Al}$ content will also lead to the increase of inclusion content and size [15]. It means that the reduction of Al content is also very likely to be one of the reasons for the refinement and reduction of inclusion content.
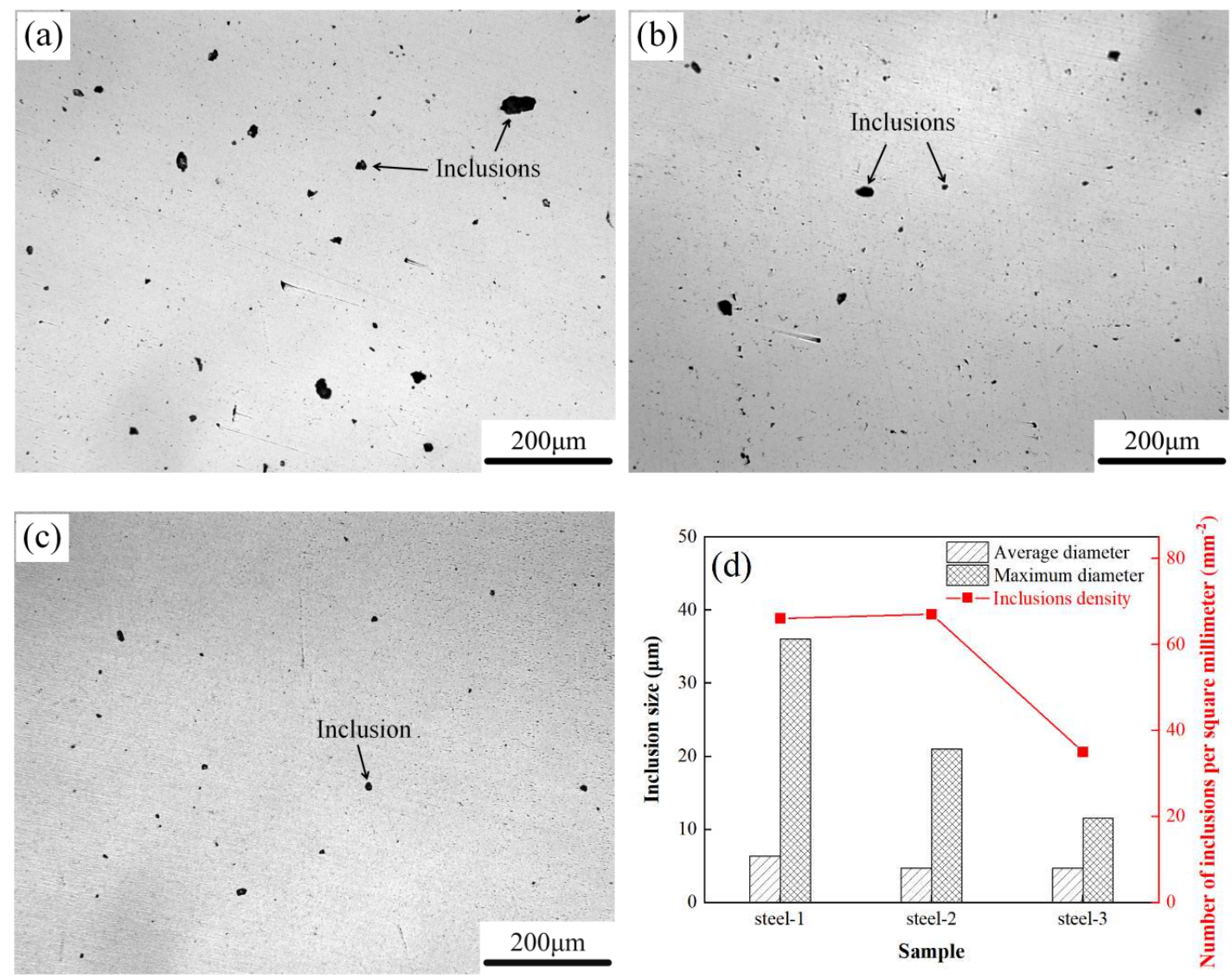

Figure 1. Morphology $(\mathbf{a}-\mathbf{c})$ and size (d) of inclusions in three ferritic stainless steels: (a) steel-1, (b) steel-2, and (c) steel-3.

Due to the slight difference of $\mathrm{Nb}$ content among the three steels, it is considered that the ferrite grain size may also be different. Figure 2 shows the morphology and size distribution of ferrite grains of the three steels by using EBSD. The results indicate that the grain size of ferritic stainless steel with high $\mathrm{Nb}$ content is smaller, which should be due to the inhibition of grain growth by solute drag of solid solution $\mathrm{Nb}$ during recrystallization annealing [7]. Previous studies [16,17] suggested that reducing the grain size is also 
helpful to improve the resistance to intergranular corrosion. Therefore, ferrite grain size and inclusions are considered as two factors that affect the HTUC behavior of ferritic stainless steel.
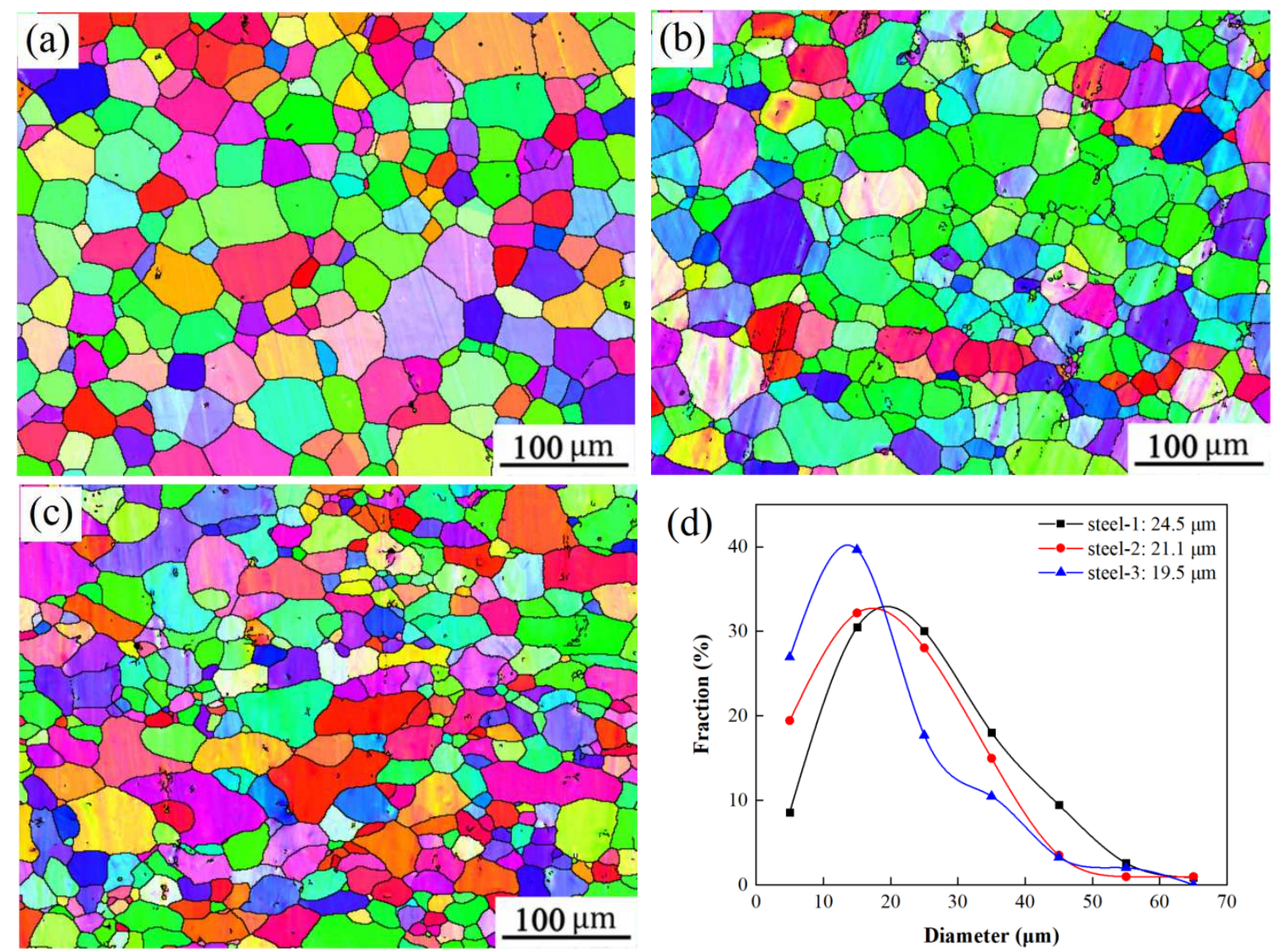

Figure 2. Morphology $(\mathbf{a}-\mathbf{c})$ and size distribution $(\mathbf{d})$ of ferrite grains in three ferritic stainless steels: (a) steel-1, (b) steel-2, (c) steel-3, and (d) average ferrite grain size and its distribution.

Figure 3a-c shows the macro-morphology of the high-temperature urea corrosion zone in the three steels, including the oxide layer and intergranular corrosion zone. It can be clearly found that the depth of the corrosion region decreases with the increase of the $\mathrm{Nb}$ content, indicating a decreasing trend of corrosion degree. Meanwhile, inclusions with different sizes can also be observed in the intergranular corrosion zone. Figure $3 \mathrm{~d}$ displays the total penetration depth of the three steels, including the average thickness reduction. Steel-3 with optimal control of ferrite grain size, inclusion size, and density shows the lowest corrosion penetration value, while this value increases with the decrease of the inclusion control level and increase of grain size. Moreover, the average thinning rate of the experimental steels also displays a decreasing trend with an increase of the $\mathrm{Nb}$ content (Table 2), which can be attributed to the coupling effect of ferrite grain size and inclusions. In order to determine the effect of inclusions on HTUC, more detailed characterizations are presented in Figures 4-6. 

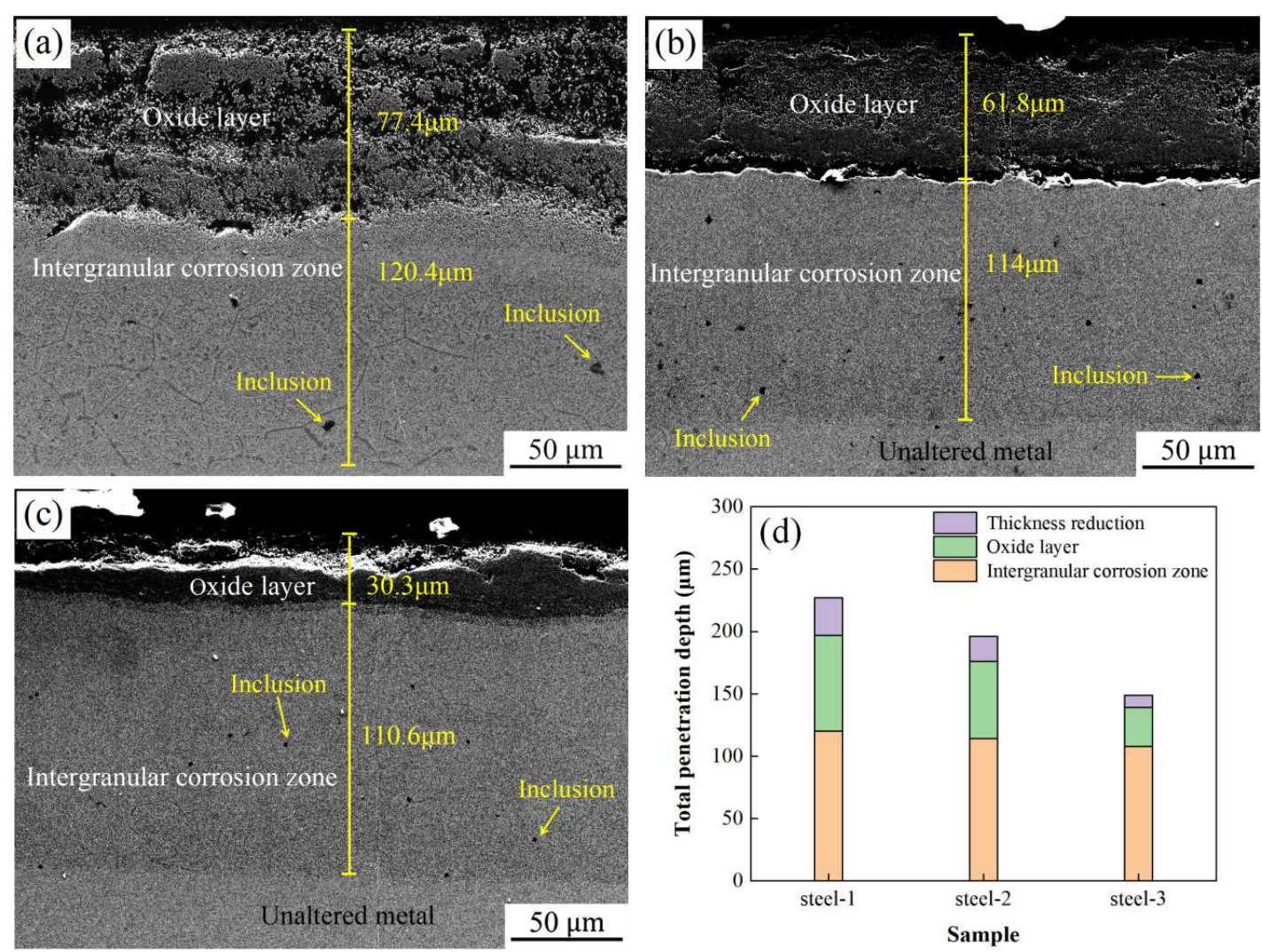

Figure 3. Morphology of urea corrosion region and depth of oxide layer and intergranular corrosion zone (a-c) and total penetration depth (d): (a) steel-1, (b) steel-2, (c) steel-3, and (d) total penetration depth of the three steels.

Table 2. Average thinning rate of experimental steels before and after heat treatment.

\begin{tabular}{|c|c|c|c|c|c|c|}
\hline \multirow[b]{2}{*}{ No. } & \multicolumn{2}{|c|}{ Before Heat Treatment } & \multicolumn{2}{|c|}{ After Heat Treatment } & \multirow{2}{*}{$\begin{array}{l}\Delta \text { Weight } \\
\text { (g) }\end{array}$} & \multirow{2}{*}{$\begin{array}{l}\text { Thinning Rate } \\
\left(\mathrm{g} /\left(\mathrm{s} \cdot \mathrm{mm}^{2}\right)\right)\end{array}$} \\
\hline & Weight (g) & $\begin{array}{l}\text { Thickness } \\
(\mathrm{mm})\end{array}$ & Weight (g) & $\begin{array}{c}\text { Thickness } \\
(\mathrm{mm})\end{array}$ & & \\
\hline steel-1 & 12.90 & 1.12 & 12.35 & 1.09 & 0.55 & $1.70 \times 10^{-7}$ \\
\hline steel-2 & 13.37 & 1.16 & 13.01 & 1.14 & 0.36 & $1.11 \times 10^{-7}$ \\
\hline steel-3 & 13.01 & 1.14 & 12.90 & 1.13 & 0.11 & $0.34 \times 10^{-7}$ \\
\hline
\end{tabular}

The enlarged images of intergranular corrosion zone before and after etching with a solution of copper chloride, hydrochloric acid, and ethyl alcohol are given in Figure 4a-c. It can be found that the precipitates (red arrow) in the urea corrosion zone are dark gray in the sample without etching (Figure 4b), and the precipitates around inclusions are also dark gray. On the contrary, the white and bright morphology is presented in the etched sample (Figure $4 \mathrm{a}, \mathrm{c}$ ). In addition to the formation of granular precipitates in the matrix, the precipitates along the ferrite grain boundaries are obvious. According to previous studies [1,18], these precipitates are mainly $\mathrm{CrN}$ or $\mathrm{Cr}_{2} \mathrm{~N}$ particles, which can also be verified by EDS and displayed in Figure $4 \mathrm{~d}-\mathrm{g}$. Although there are some peaks of carbon and oxygen, the main compositions of precipitate are mainly chromium and nitrogen. Compared with the unaltered metal, the ferrite grain boundaries are very clean and there are no precipitates, confirming that the formation of chromium precipitates occurs in the process of HTUC. It is worth noting that intergranular corrosion is more serious, and precipitation behavior appears to occur at the interface between inclusions and matrix. 

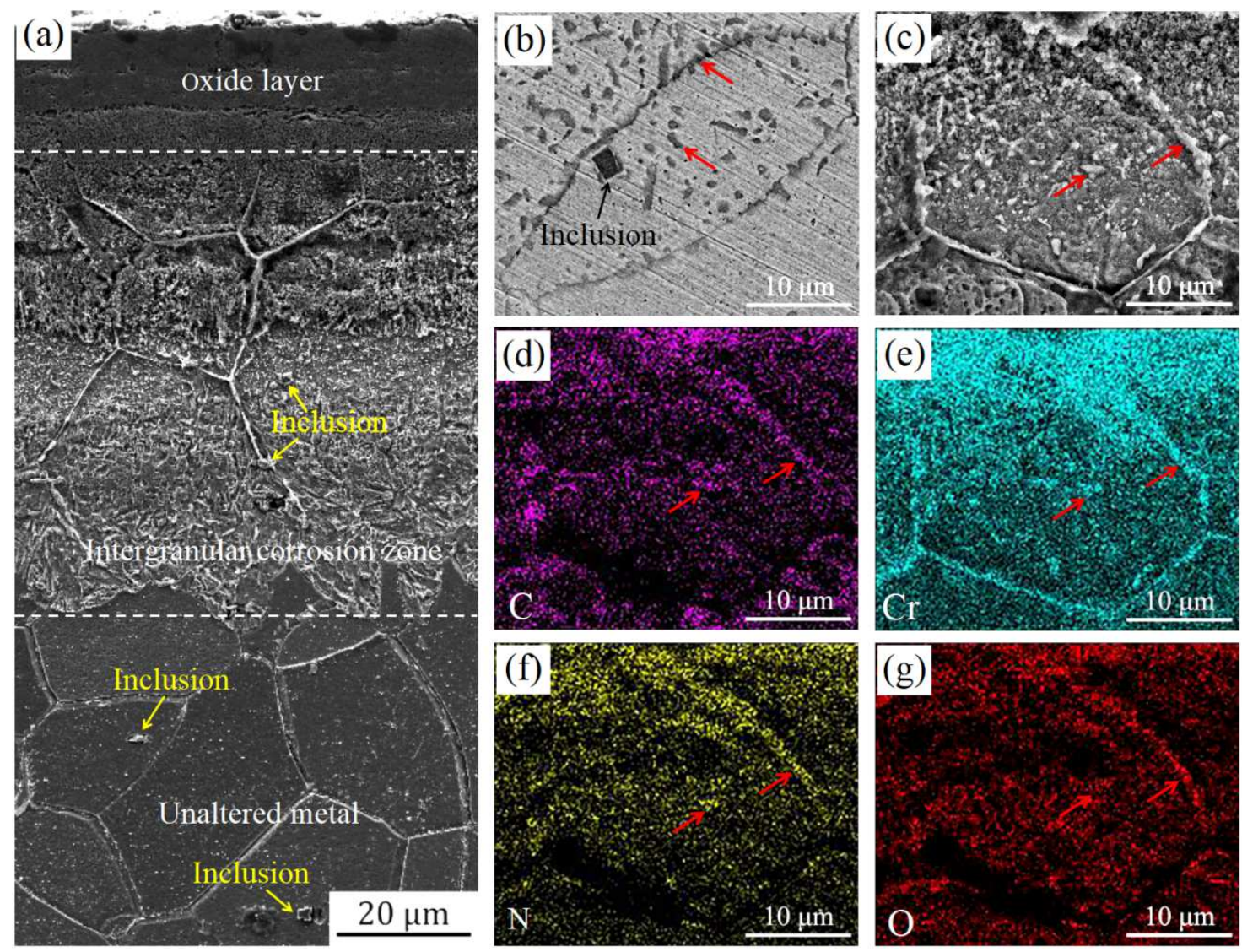

Figure 4. (a) Area scanning of the corrosion region in steel-3 after etching with a solution of copper chloride, hydrochloric acid, and ethyl alcohol, $(\mathbf{b}, \mathbf{c})$ intergranular corrosion zone before and after etching, and $(\mathbf{d}-\mathbf{g})$ EDS analysis of the corrosion products formed in (c).

In this study, thousands of inclusions were identified by SEM, and it was found that most of the inclusions in ferritic stainless steel were indeed related to Al. Therefore, Figures 5 and 6 show the morphology, structure, and element distribution of typical inclusions in the matrix (unaltered metal) and urea corrosion zone, respectively. The inclusion in Figure 5 is a composite structure with $\mathrm{Al}_{2} \mathrm{O}_{3}$ as the core and $\mathrm{TiN}-\mathrm{Nb}(\mathrm{C}, \mathrm{N})$ wrapped outside. There is no chromium enrichment at the interface between inclusion and the matrix, which can be concluded from the $\mathrm{Cr}$ distribution map (Figure 5i) and line scanning map (Figure 5j). However, in the intergranular corrosion zone (Figure 6), Cr-rich precipitates formed at the interface between $\operatorname{TiN}-\mathrm{Nb}(\mathrm{C}, \mathrm{N})$ inclusion and the ferrite matrix. It is proved that the interface between ferrite and inclusion is also the channel of chromium precipitation. Compared with the matrix, it is reasonable to believe that the precipitation rate of chromium at the interface should be much higher than that of the matrix. When the inclusion content is high and the size is large, many "Cr-depleted zones" will preferentially form near the interface between inclusions and matrix. Thus, intergranular corrosion will be induced by the electrochemical potential difference between the matrix and a $\mathrm{Cr}$ depleted zone adjacent to the inclusion enclosed by $\mathrm{Cr}$-rich precipitates $[19,20]$, leading to the reduction of the resistance to HTUC. This should be one of the key factors for the weakest resistance to HTUC of steel-1. In addition, high-temperature thermal fatigue will further aggravate the effect of inclusions with large size. 

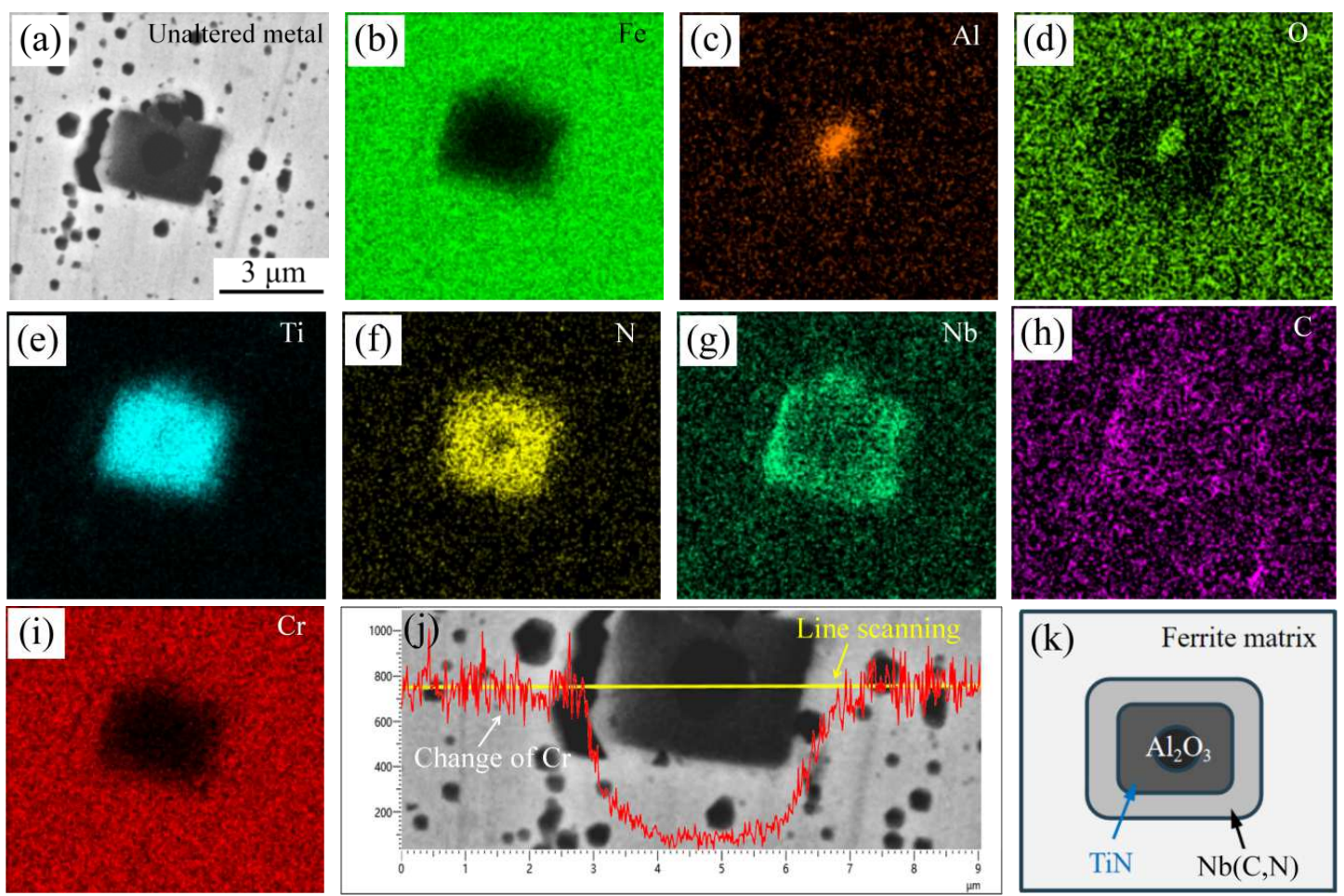

Figure 5. Morphology, structure, and element distribution of inclusion in a steel-3 matrix (unaltered metal): (a) $\mathrm{Al}_{2} \mathrm{O}_{3}-\mathrm{TiN}^{-}$ $\mathrm{Nb}(\mathrm{C}, \mathrm{N})$ composite inclusion in ferrite matrix before HTUC, (b-i) area scanning of the inclusion by using EDS, (j) line scanning by using EDS to show the $\mathrm{Cr}$ distribution, and (k) schematic diagram of composite inclusion.
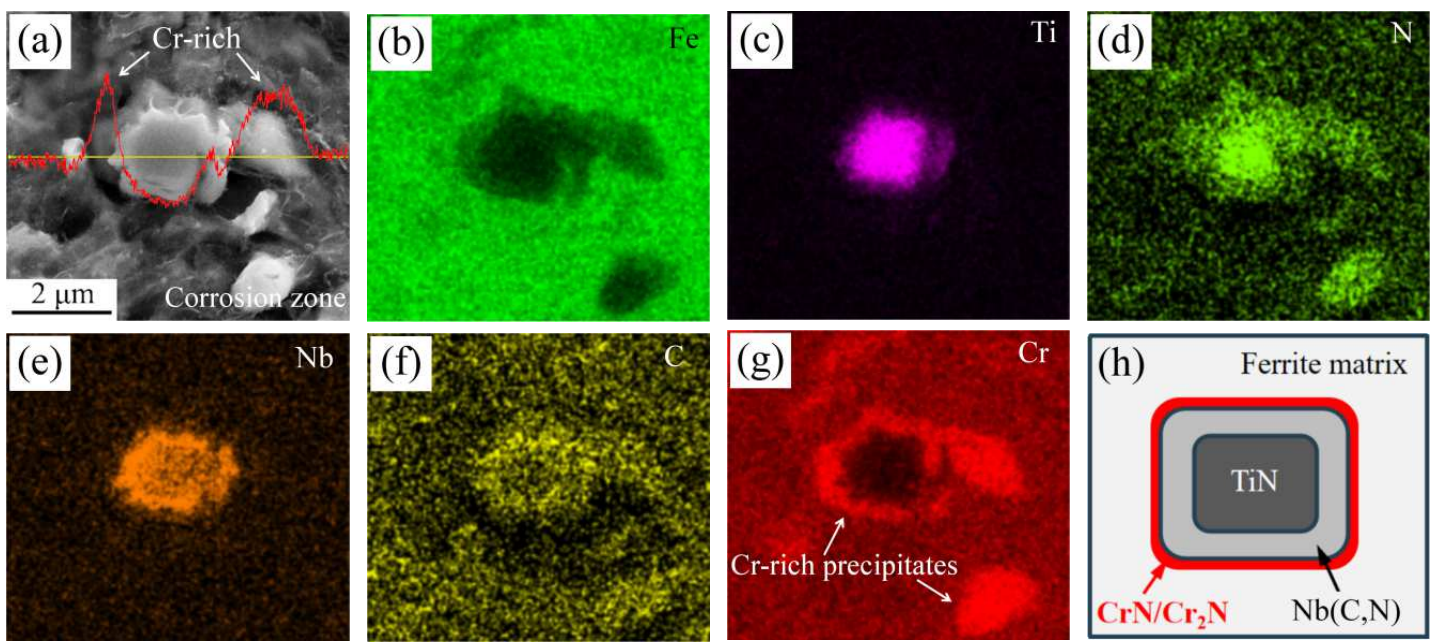

Figure 6. Morphology, structure, and element distribution of inclusion in intergranular corrosion zone in steel-3: (a) TiN$\mathrm{Nb}(\mathrm{C}, \mathrm{N})$ composite inclusion after HTUC and line scanning by using EDS to show the Cr distribution, (b-g) area scanning of the inclusion by using EDS, and (h) schematic diagram of composite inclusion.

From the experimental evidence gathered and presented in this study, it is found that inclusion is also one of the key factors affecting the corrosion of materials. A previous study [21] has also pointed out that inclusions are incoherence with ferritic stainless steel in crystal structure, and crevice corrosion may happen between inclusion and the matrix, which makes the self-reparation of the passive film difficult. Therefore, the stainless steel with large size and high content of inclusions is more sensitive to HTUC. Reducing the content and size of inclusions while refining the grain will significantly improve the resistance of ferritic stainless steel to HTUC so as to reduce the sensitized zone of the steel 
to ensure that the chromium equivalent of the matrix is not less than $12 \%$ [2,22]. Moreover, adding $\mathrm{Nb}$ is proved to be an effective way to refine inclusions, which is consistent with the results of a previous study [6]. Nb is also beneficial for the high-temperature performance, especially thermal fatigue resistance, which can promote the formation of a Laves phase at the oxide layer/metal matrix interfaces and thus prevent the diffusion of cations to the oxide layer and inhibit the oxygen ions from entering the stainless steel [6]. Moreover, the binding force of $\mathrm{Nb}$ with $\mathrm{C}$ and $\mathrm{N}$ atoms is stronger than that of $\mathrm{Cr}$, which impedes the formation of $\mathrm{Cr}_{3} \mathrm{C}_{2}$ [14]. Therefore, the sensitization area can be effectively reduced and then decline the corrosion rate. However, the addition of $\mathrm{Nb}$ will increase the production cost of stainless steel. If the inclusion can also be controlled by metallurgical method, it will be a more cost-effective technology, such as strict control of Al-deoxidation process.

\section{Conclusions}

(1) In the SCR system, ferritic stainless steel will be affected by high-temperature urea corrosion, forming an oxide layer and intergranular corrosion zone along the thickness direction. Nitrogen atoms penetrate into the matrix and combine with $\mathrm{Cr}$ to produce intergranular precipitation and intergranular corrosion. At the same time, a layer of oxide film will be formed on the surface during high-temperature oxidation process. Due to the thermal fatigue effect, the oxide film will gradually fall off, thus aggravating the corrosion of stainless steel.

(2) As an unfavorable factor in steel, inclusions also seriously affect the high-temperature urea corrosion resistance. The results show that refining inclusions and reducing their content by slightly increasing of $\mathrm{Nb}$ content can improve the high-temperature urea corrosion resistance of ferritic stainless steel. The underlying mechanism is that the interface between inclusions and the matrix can induce the precipitation of chromium nitrides, resulting in the chromium equivalent of the matrix decrease and inducing micro interface corrosion. Accompanying with the effect of thermal fatigue, the corrosion thinning rate of ferritic stainless steel increases and the service life decreases.

(3) $\mathrm{Nb}(\mathrm{C}, \mathrm{N})$ encapsulates inclusions such as TiN to inhibit its coarsening, thus reducing the precipitation of chromium nitride at the interface of inclusions and matrix, so as to ensure the high-temperature urea corrosion resistance of ferritic stainless steel and reduce the tendency of crack initiation induced by inclusions.

Author Contributions: X.W. contributes primarily to the writing and compilation of manuscript and data analysis; Q.L. and W.Z. are heavily involved in the project conceptualization, administration, and planning; Z.X. contributes primarily to carrying out the main experiments and data collection; C.S. is in charge of reviewing and editing the manuscript. All authors have read and agreed to the published version of the manuscript.

Funding: This research was funded by the National Natural Science Foundation of China (No. 52001023).

Institutional Review Board Statement: Not applicable.

Informed Consent Statement: Not applicable.

Data Availability Statement: Data is contained within the article or supplementary material.

Conflicts of Interest: The authors declare no conflict of interest.

\section{References}

1. Saedlou, S.; Santacreu, P.; Leseux, J. Suitable Stainless Steel Selection for Exhaust Line Containing a Selective Catalytic Reduction (SCR) SYSTEM; SAE International: Warrendale, PA, USA, 2011.

2. Wang, X.L.; Huang, A.R.; Li, M.X.; Zhang, W.; Shang, C.J.; Wang, J.L.; Xie, Z.J. The signifificant roles of Nb and Mo on enhancement of high temperature urea corrosion resistance in ferritic stainless steel. Mater. Lett. 2020, 269, 127660. [CrossRef]

3. Chen, C.; Shang, C.J.; Song, X.; Bi, H.Y.; Fan, G.W.; Hou, H.R. Condensate corrosion behavior of new style ferritic stainless steels used in automotive exhaust system. Iron Steel 2009, 44, 78-81. 
4. Nockert, J.; Nyborg, L.; Norell, M. Corrosion of stainless steels in simulated diesel exhaust environment with urea. Mater. Corros. 2011, 63, 388-395. [CrossRef]

5. Wei, L.L.; Chen, L.Q.; Ma, M.Y.; Liu, H.L.; Misra, R.D.K. Oxidation behavior of ferritic stainless steels in simulated automotiveexhaust gas containing 5 vol.\% water vapor. Mater. Chem. Phys. 2018, 205, 508-517. [CrossRef]

6. Li, M.X.; Zhang, W.; Wang, X.L.; Chen, E.H.; Chen, C.; Zhang, H.W.; Shang, C.J. Effect of Nb on the performance of 409 stainless steel for automotive exhaust systems. Steel Res. Int. 2018, 89, 1700558. [CrossRef]

7. Tanure, L.; Alcântarac, C.M.; Santos, D.B.; Oliveirac, T.R.; Gonzalez, B.M.; Verbeken, K. Microstructural characterization and mechanical behavior during recrystallization annealing of $\mathrm{Nb}$-stabilized type ASTM 430 and Nb-Ti-stabilized ASTM 439 ferritic stainless steels. J. Mater. Res. Technol. 2019, 8, 4048-4065. [CrossRef]

8. Liu, C.; Revilla, R.I.; Liu, Z.Y.; Zhang, D.W.; Li, X.G.; Terryn, H. Effect of inclusions modified by rare earth elements (Ce, La) on localized marine corrosion in Q460NH weathering steel. Corros. Sci. 2017, 129, 82-90. [CrossRef]

9. Zheng, S.Q.; Li, C.Y.; Qi, Y.M.; Chen, L.Q.; Chen, C.F. Mechanism of (Mg,Al,Ca)-oxide inclusion-induced pitting corrosion in 316L stainless steel exposed to sulphur environments containing chloride ion. Corros. Sci. 2013, 67, 20-31. [CrossRef]

10. Vuillemin, B.; Philippe, X.; Oltra, R.; Vignal, V.; Coudreuse, L.; Dufour, L.C.; Finot, E. SVET, AFM and AES study of pitting corrosion initiated on MnS inclusions by microinjection. Corros. Sci. 2003, 45, 1143-1159. [CrossRef]

11. Zhang, J.M.; Li, S.X.; Yang, Z.G.; Li, G.Y.; Hui, W.J.; Weng, Y.Q. Influence of inclusion size on fatigue behavior of high strength steels in the gigacycle fatigue regime. Int. J. Fatigue 2007, 29, 765-771. [CrossRef]

12. Cheng, P.Z.; Zhong, N.; Dai, N.W.; Wu, X.; Li, J.; Jiang, Y.M. Intergranular corrosion behavior and mechanism of the stabilized ultra-pure 430LX ferritic stainless steel. J. Mater. Sci. Technol. 2019, 35, 1787-1796. [CrossRef]

13. Hu, S.; Han, E.H.; Liu, X.B. Atomic-scale evidence for the intergranular corrosion mechanism induced by co-segregation of low-chromium ferritic stainless steel. Corros. Sci. 2021, 189, 109588. [CrossRef]

14. Ma, X.P.; Miao, C.L.; Langelier, B.; Subramanian, S.V. Suppression of strain-induced precipitation of NbC by epitaxial growth of $\mathrm{NbC}$ on pre-existing TiN in Nb-Ti microalloyed steel. Mater. Des. 2017, 132, 244-249. [CrossRef]

15. Li, J.Y.; Cheng, G.G.; Ruan, Q.; Li, J.C.; Pan, J.X.; Chen, X.G. Evolution mechanism of inclusions in Al-killed, Ti-bearing 11Cr stainless steel with Ca treatment. ISIJ Int. 2018, 58, 1042-1051. [CrossRef]

16. Li, S.X.; He, Y.N.; Yu, S.R.; Zhang, P.Y. Evaluation of the effect of grain size on chromium carbide precipitation and intergranular corrosion of 316L stainless steel. Corros. Sci. 2013, 66, 211-216. [CrossRef]

17. Gu, J.; Zhang, L.; Ni, S.; Song, M. Effects of grain size on the microstructures and mechanical properties of 304 austenitic steel processed by torsional deformation. Micron 2018, 105, 93-97. [CrossRef] [PubMed]

18. Simmons, J.W.; Covino, B.S.; Hawk, J.A.; Dunning, J.S. Effect of nitride (Cr2N) precipitation on the mechanical, corrosion, and wear properties of austenitic stainless steel. ISIJ Int. 1996, 36, 846-854. [CrossRef]

19. Kim, J.K.; Kim, Y.H.; Kim, K.Y. Influence of Cr, C and Ni on intergranular segregation and precipitation in Ti-stabilized stainless steels. Scr. Mater. 2010, 63, 449-451. [CrossRef]

20. Jeon, S.H.; Kim, H.J.; Park, Y.S. Effects of inclusions on the precipitation of chi phases and intergranularcorrosion resistance of hyper duplex stainless steel. Corros. Sci. 2014, 87, 1-5. [CrossRef]

21. Chen, C.; Lu, X.H.; Zheng, Y.; Shang, C.J.; Xiao, J.M. Influence of precipitate behavior on condensate corrosion resistance for type 439 ferritic stainless steels. J. Iron Steel Res. 2011, 23, 47-53.

22. Bi, H.Y.; Kokawa, H.; Wang, Z.J.; Shimada, M.; Sato, Y.S. Suppression of chromium depletion by grain boundary structural change during twin-induced grain boundary engineering of 304 stainless steel. Scr. Mater. 2003, 49, $219-223$. 